\title{
JOURNAL OF ANATOMY AND PHYSIOLOGY
}

ON THE SURGICAL ANATOMY OF THE PROSTATE. (The introduction to a discussion on the Surgical Anatomy of the Prostate at the Anatomical Society of Great Britain and Ireland, November 21, 1905.) By J. W. Thomson Walker, M.B., F.R.C.S., Assistant Surgeon to the North-West London Hospital and to St Peter's Hospital for Stome and other Urinary Diseases.

I wUs' in the first place thank the Anatomical Society for the invitation to introduce this discussion on the Surgical Anatomy of the Prostate, and I am the more sensible of the honour since I cannot lay claim to rank as a teacher of anatomy.

During the past few years the prostate gland has been the subject of some surgical adventure and much surgical writing. It is but meet, therefore, that the anatomy of the organ should be carefully revised, so that the work and statements of the surgeon and the anatomist nay fall into line.

During the renaissance of prostatic surgery, I was struck by the divergence of views that existed, not only in regard to the operative measures, but also in regard to the anatomy of the organ. I found that the standard works on anatomy differed in certain particulars, or even passed by unnoticed, certain points that appeared to be important from the surgical stand-point.

I therefore commenced an investigation in 1902, with the object of tracing the anatomical lines of the operation of prostatectomy. The remarks I shall make to-day are based upon part of this work, and were published in outline in 1904. I have revised the work by recent dissections, and have found no reason to alter the statements then made.

This is neither the time nor the place for a systematic description of the VOL. XL. (THIRD SER. VOL. I.) -APR. 1906. 
anatomy of the prostate. I shall only take up certain points which appear to me important surgically.

\section{The Sheath.}

The prostate is surrounded by a layer of fascia which envelops it except at its basal attachment to the bladder. At the apex of the gland this sheath blends with the muscular tissue surrounding the urethra. Sir

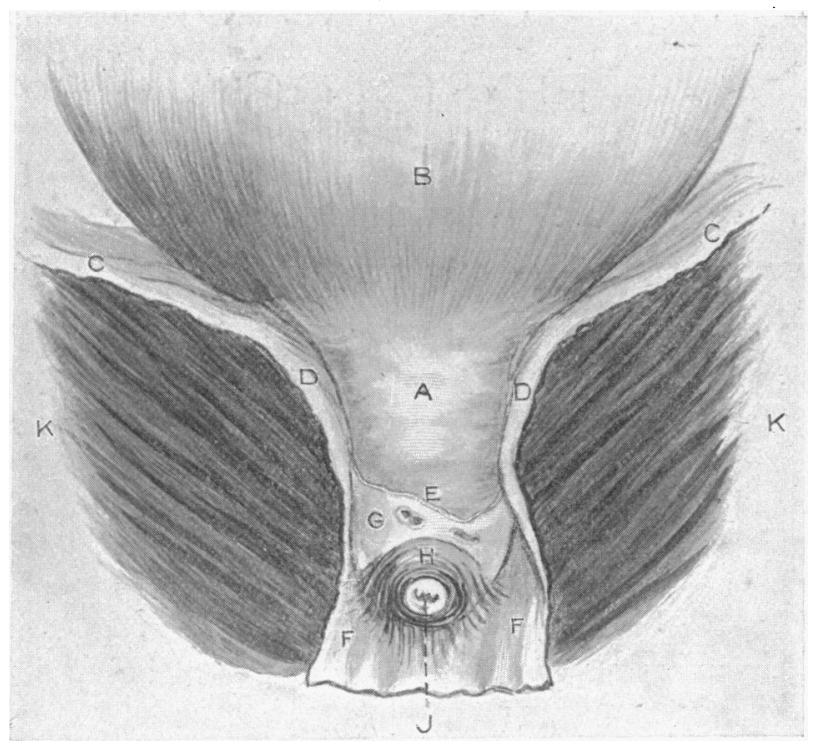

FIG. 1. - Undissected prostate and surrounding tissues removed from body. Anterior surface.

A, Part of anterior surface of prostate between reflected lateral layers of sheath. B, Anterior wall of bladder. C, Rectovesical fascia on upper surface of levator ani muscle. $D$, Vertical line of reflexion of fascia on anterior surface of prostate. $E$, Line of reflexion of fascia crossing middle line. F, Upper layer of triangular ligament. $G$, Apox of prostate showing termination of dorsal vein of penis. $H$ Striped muscle surrounding urethra. J, Urethra. $\mathbf{K}$, Levator ani muscle.

Henry Thompson described this fascial envelope as the "sheath" in his work on the prostate, and although the term has not been widely adopted by anatomical writers, I have used it here, as it clearly distinguishes this layer of fascia from the tissue immediately surrounding the prostate gland which Thompson called the capsule.

This sheath is derived from the rectovesical layer of pelvic fascia.

The rectovesical layer of pelvic fascia passes inwards from the side wall of the pelvis on the upper surface of the levator ani muscle, and meets the 
lateral aspect of the junction of the bladder and prostate, where it becomes firmly attached (fig. 1, C).

A layer of fascia passes up from this attachment and covers the wall of the bladder. A strong layer passes downwards over the lateral aspect of the prostate, and forms the lateral portion of the sheath.

If this lateral layer be traced forwards, it will be found to pass on to the anterior surface of the prostate; but before reaching the middle line it turns

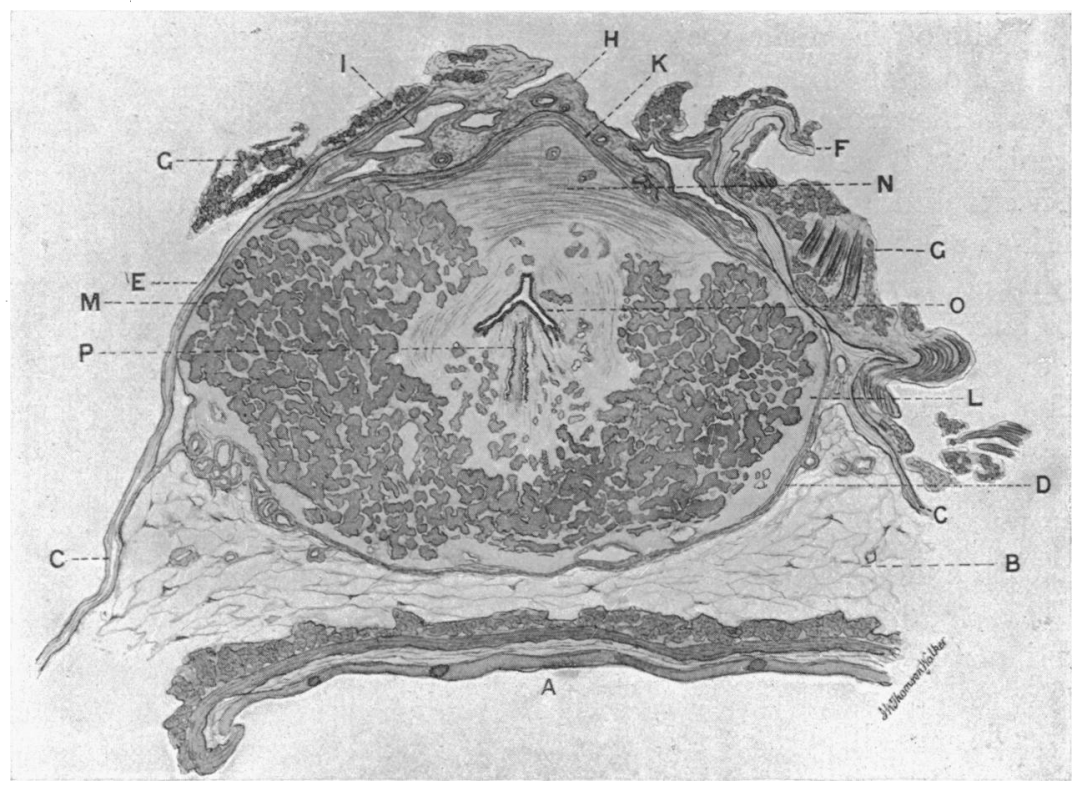

Fia. 2.-Horizontal section of prostate at level of verumontanum.

A, Rectum. B, Areolar tissue between rectum and prostate. C, Rectovesichl fascia: D, Layer of fascia on posterior surface of prostate. $E$, Layer of fascia on side of prostate. $F$, Reflexion of fascia from prostate. G, Levator ani muscle. $H$, Layer of fascia on anterior surface of prostate. I, Veins of prostatic plexus. K, Layer of striped muscle. L, M, Margin of stroma forming capsule. $\mathrm{N}$, Anterior commissure. 0 , Urethra with verumontanum. P, Ejaculatory ducts.

forwards away from the gland, so that at the anterior surface towards the base an interval about the breadth of a finger is left uncovered (fig. 1, A).

As the prostate narrows towards its apex, the line of reflexion, which is vertical, approaches the lateral margin, and, at about the lower third of the organ, appears to pass away from it altogether. On more careful examination the cut edge of a thin layer of fascia is found passing across the front of the prostate, about its lower third, and joining the two lateral reflexions where they are commencing to pass off the prostate (fig. 1, E). 
We see, therefore, that the line of attachment of fascia passes along the side of the prostate at its junction with the bladder, and then turns vertically downwards on the front of the organ and is then continued across the middle line.

The anterior surface of the prostate between these two vertical lines of reflexion is covered in by a special layer of fascia to which I shall again refer.

The posterior surface of the prostate is covered in by a layer of fascia which splits off from the rectovesical fascia. This posterior layer is firmly attached along the line of the base of the prostate, and a further prolongation upwards from this line covers in the seminal vesicles and vasa deferentia and passes up over the ureters on the back of the bladder.

On examining a thick microtome section of the prostate and its surroundings at the level of the verumontanum, the rectovesical fascia is seen as a distinct layer (fig. 2). From the side of the rectum it passes forwards to the lateral surface of the prostate. On reaching the prostate it gives off a layer of fascia which may be traced on the posterior surface of that organ. It then passes forwards, covering the lateral and anterior surfaces of the prostate, but before reaching the middle line it passes outwards away from the gland. The space between the two reflected layers is covered in by tissue which differs in some particulars from the rest of the sheath and will be considered later.

These layers of rectovesical fascia are more easily distinguished by dissection than by microscopical section. In the section here described they are well seen, but in thin, lightly stained sections and in some prostates they are less readily followed.

Under the microscope the fascia consists of wavy fibres with a few nuclei. The fibres may be loosely set, but where the membrane is well defined they are closely packed.

Let us now return to the dissection of the sheath. If the levator ani be thrown back from the side of the prostate, the lateral surface of the sheath is exposed. This is readily picked up with forceps, and an incision may be made through it and a probe introduced between the fascia and the prostate (fig. 3). The sheath can now be stripped upwards towards the base. On reaching the base, however, the lobe of the prostate is adherent to the bladder, and any further stripping is prevented by the adhesion of the sheath along this line and by muscular fibres passing from the bladder wall into the prostate.

On stripping the fascia downwards, it peels off readily until the apex is almost reached. Here, coarse muscular fibres are found to lie between the sheath and the organ. These I shall show later to be striped muscle 
fibres. Further stripping is prevented by the sheath being bound down around the apex. On stripping the sheath backwards, the probe can be made to pass across the middle line, and with a little care the whole of the posterior surface of the gland can be bared of its sheath. The stripping on this aspect, as on the lateral surfaces, is only limited at the apex and at the base of the gland.

On stripping the sheath forwards, however, it is found that it is firmly

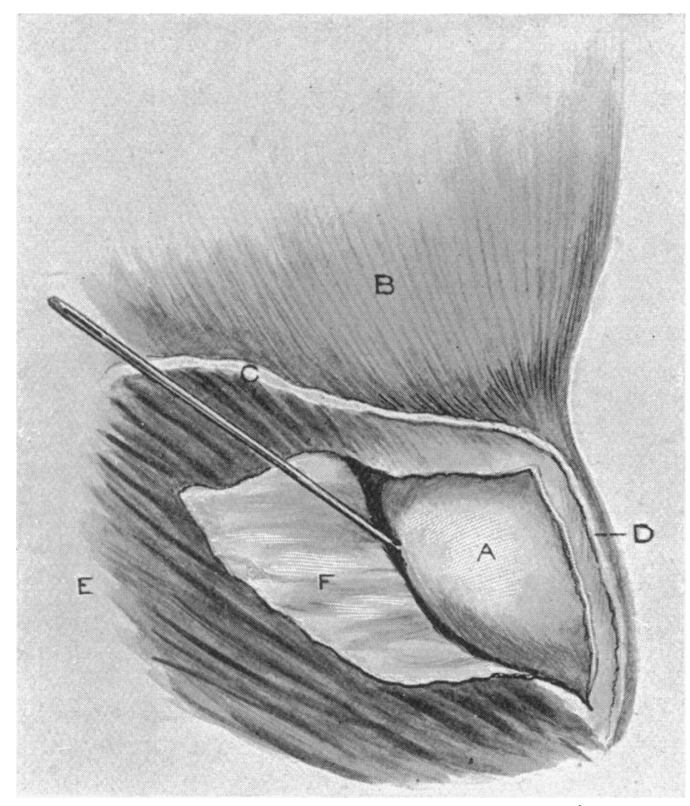

Fig. 3. - Lateral view of prostate and bladder.

A, Right lobe of prostate exposed. B, Bladder. C, Line of attachment of rectovesical fascia. D, Line of reflexion of fascia from anterior surface of prostate. $\mathbf{E}$, Levator ani muscle. F, Lateral layer of fascial sheath thrown back. A probe has been passed behind the prostate inside the sheath.

adherent along a broad vertical band at the front of the prostate. In order to turn up the sheath here it is necessary to cut through a layer of tissue : no line of separation can be produced by teasing.

I have had occasion to notice this portion of the sheath already, and shall now consider it a little more in detail. On the surface of the sheath this band is marked out on each side by the vertical lines of reflexion of the lateral layers of the sheath. Stoney ${ }^{1}$ has pointed out that a portion

1 Jour. Anat. and Phys., vol. xxxviii., and also Trans. Royal Acad. of Med. of Dublin, 1904. 
of the front of the prostate, where the visceral layer of fascia dips down, is covered by what is really the vesical reflexion of the fascia. This corresponds to the vertical band that I have just described as being adherent along the front of the prostate, although in my specimens the dipping downwards of the visceral layer of fascia on the front of the prostate appears to have been greater than in the description given by this observer, for he found the transverse attachment about the middle of the organ, while my dissections showed it lower down. In any case there is a strip in the front of the prostate from the base downwards for some distance which is bounded on either side by the reflexion of the lateral layers and below by the continuation of these across the middle line, which receives a covering different from the rest of the sheath.

By careful dissection the layer which corresponds to the vesical reflexion at the sides may be stripped off, and beneath it is found a band of tissue along the front of the prostate, firmly adherent to the organ. Microscopical sections made horizontally through the prostate at this level show that the fibres of this portion of the sheath are less regularly arranged than elsewhere, and that embedded in its substance are masses of fat and bands of non-striped muscle, and that the large venous channels on the front of the prostate lie among its fibres. Further, a thin layer of striped muscle fibres, to which I shall again refer, lies between this and the non-striped muscle of the gland stroma (fig. 2).

It will be seen, therefore, that the prostate lies in a sheath of fascia as an egg fills an egg-cup, and that it is loosely set in this cup of fascia except at the apex, where the fascia becomes incorporated with the striped muscle surrounding the urethra, and along the anterior surface.

\section{The Relation of the Prostate to the Bladder Base.}

The prostate is adherent at its base to the under surface of the bladder wall.

The area of the bladder base, which the organ underlies, surrounds the internal meatus in the form of an oval with the long axis transversely (fig. 4). In this specimen the organ extended backwards for half an inch, or to about the mid point of the trigone, and forwards for a quarter of an inch in front of the urethral opening. The greatest lateral extent was a line drawn from the meatus outwards and a little backwards, and measured nine-sixteenths of an inch on each side. This area does not, of course, map out the distribution of the gland tissue beneath the bladder base, which I shall later show does not advance in front of the urethra at this level, but it includes the base of the whole organ. 
The figures vary a good deal in different subjects, but these may act as a rough indication of the area of bladder base which the-prostate underlies.

If the mucous membrane be stripped from off the bladder base, the arrangement of the muscular bundles may be studied; and if we take advantage of the hypertrophy produced by urethral obstruction, the plan of the bladder base becomes still more evident.

The trigone of the bladder is not an artificial triangle indicated by arbitrary lines joining the ureters with each other and each. with the urethral opening, but is mapped out by a distinct arrangement of muscular fibres.

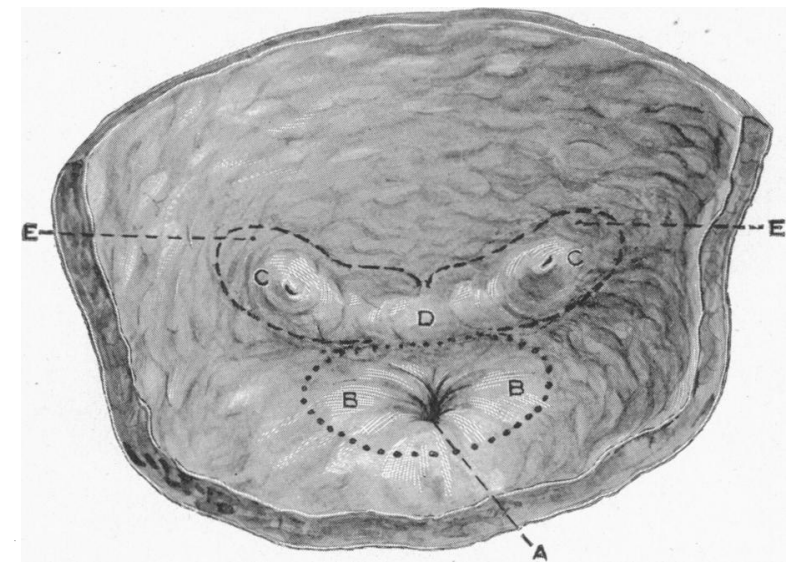

Fig. 4.-Bladder base showing relation of base of prostate and seminal vesicles. $\frac{5}{6}$.

A, Opening of urethra. B, B, Dotted line showing outline of upper surface of base of prostate. C, C, Openings of ureters. D, Interureteral bar. E, Dotted lines showing outlines of seminal vesicles.

Joining each ureteral opening is a muscular band known as Mercier's bar, evident in most bladders, but well raised and thick where urethral obstruction has led to hypertrophy.

From the ureter on each side a thick band of muscle passes down towards the urethra. These bands converge and unite so that this longitudinal muscle flows over the margin of the urethral opening in a continuous sheet.

In the centre of the triangle formed by these bands of muscle the fibres appear to interlace indiscriminately. On either side of, and behind, this muscular trigone the circular muscle of the bladder may be distinguished.

The further relations of the muscular bladder base to the base of the prostate are best studied by examining microtome sections. 
In a sagittal section of the prostate through the urethra a thick layer of non-striped muscle is seen lying on the upper surface of the prostate (fig. 5). If the layers of the posterior bladder wall are traced towards the prostate, the outer longitudinal layer becomes lost upon the upper surface of the gland. The fibres gradually become incorporated with the non-striped muscle of the stroma of the organ. In front of the urethra the longitudinal layer of muscle approaches the anterior wall of the canal and becomes lost among the bundles of circular, non-striped muscle which surround it. The circular layer of bladder muscle, when traced from the posterior wall, approaches the

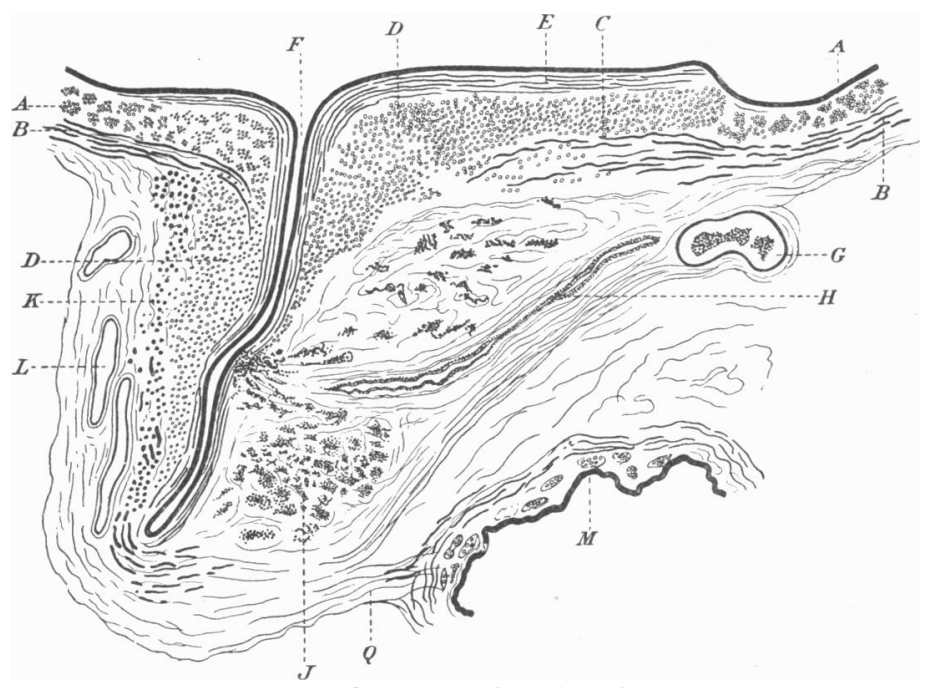

Fig. 5. - Medium sagittal section of prostate.

A, Circular layer of bladder muscle. B, Longitudinal layer of bladder muscle. C, Circular layer of trigone muscle. D, Unstriped sphincter of bladder. E, Longitudinal layer of trigone muscle. F, Urethria. G, Right seminal vesicle. H, Ejaculatory duct. J, Prostatic gland tissue. K, Striped muscle on front of prostate. L, Veins of prostatic plexus. M, Rectum. Q, Recto-urethral muscle.

base of the prostate, but, before reaching it, is replaced by a thicker layer of circular muscle the fibres of which are more closely set. From the anterior wall the circular layer passes quite down to the urethra and then blends with the circular muscle surrounding this tube.

When the muscle lying directly upon the prostatic base is examined, the arrangement is found to differ considerably from that of the bladder wall. A few fibres of the outer longitudinal layer of the posterior bladder wall are found intermingling with the muscular covering and with the non-striped muscle of tlie prostatic stroma. The circular layer of bladder muscle is, however, replaced by a layer of fibres which are more compactly 
set, and, although circularly arranged, may be readily distinguished from those of the bladder wall. This layer, as it approaches the urethra, becomes thicker and forms a thick wedge behind the opening of the urethra. Hence it is continued downwards as a thin layer of circular muscle surrounding the urethra. In front of the urethra no such flat layer exists, but, as already stated, the circular bladder muscle is continued well up to the urethra. Along the front wall of the urethra, however, is a thick band of circular muscle, similar in its compact arrangement to that lying upon the base of the gland, and extending as a gradually thinning layer to the apex of the prostate.

Lying beneath the bladder mucous membrane over the flat wedge of circular muscle is a longitudinal layer of non-striped muscle. This commences about the posterior border of the compact circular layer, and passes forwards as far as the urethra, where it dips down to form the internal longitudinal layer of that canal. In front of the urethra these longitudinal fibres commence only a short way in front of the urethral opening, and pass backwards into the wall of the canal.

In sagittal sections more laterally placed (fig. 6), this circular and longitudinal arrangement of muscle on the bladder base maintains almost until the region of the ureteral opening is reached. In a section at the latter plane, one lobe of the prostate is seen cut vertically, and above it is a continuous layer of the outer longitudinal bladder muscle; above this, again, is the circular bladder muscle, on the surface of which is seen the commencement of the ureter. It will be recognised, therefore, that this layer of compact circular muscle and the longitudinal fibres lying upon it constitute the trigone of the bladder, and that the well-marked posterior margin of these forms the interureteral bar of Mercier.

What then constitutes the non-striped vesical sphincter? In my previous writings I have looked upon the whole of this flat layer of circular muscle as constituting the sphincter, and I find that this is in agreement with the view of Kalischer, as quoted by Frisch and Zuckerkandl in their work on Urology, published in 1904. Kalischer describes the sphincter as a fan-shaped muscle, the anterior part of which is spread out along the anterior surface of the prostatic urethra. Frisch and Zuckerkandl, however, regard only the wedge-shaped portion abutting upon the urethral orifice as the vesical sphincter. Their argument, that the rest of the circular trigone muscle must be at a disadvantage as regards sphincter action when flattened out in the distended bladder, seems a sensible one.

With the microscope the limits of the non-striped muscular prostatic stroma and of the overlying muscle of the trigone are by no means clearly 
defined. The bundles of non-striped muscle intermingle, so that it is difficult to say along what line the prostatic stroma ceases and the muscle fibres of the bladder base commence. Further outwards, however, where the muscle of the trigone is replaced by the layers of the bladder wall, the

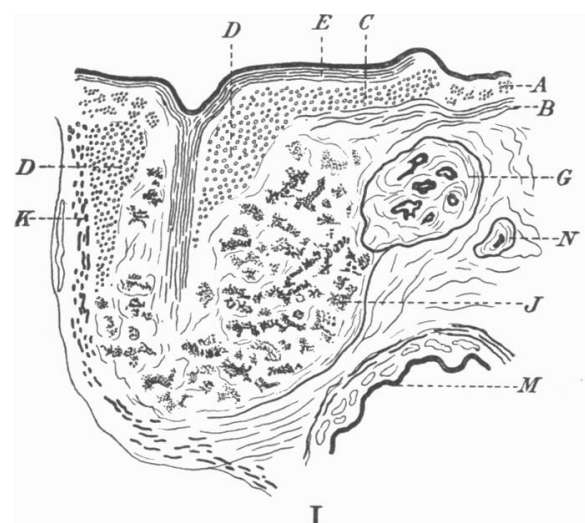

I

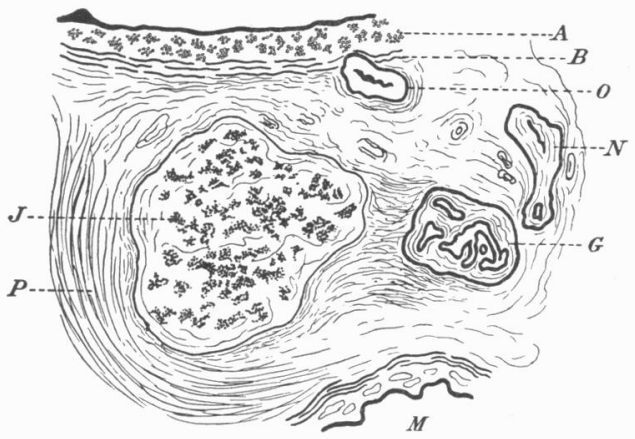

III

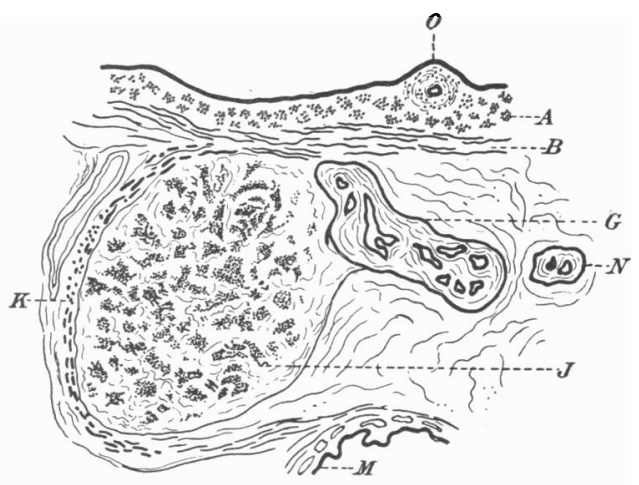

ПI

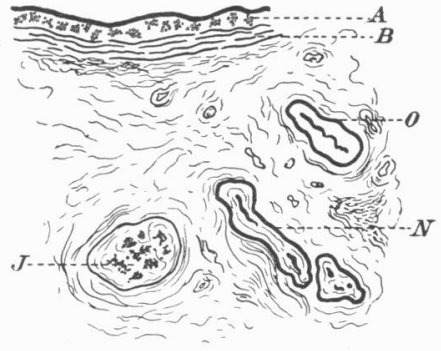

IV

Fic. 6. - Series of sagittal sections of prostate and surroundings to follow fig. 5. These sections commence at the middle line and pass to the right.

A, Circular layer of bladder muscle. B, Longitudinal layer of bladder muscle, $C$, Circular layer of trigone muscle. D, Unstriped sphincter of bladder. E, Longitudinal layer of trigone muscle. G, Right seminal vesicle. J, Prostatic gland tissue. K, Striped muscle on front of prostate. M, Rectum. N, Vas deferens. $O$, Right ureter. P, Levator ani muscle.

definition is sharp, for the outer longitudinal layer of bladder muscle here shows no tendency to mingle with the fibres of the prostatic stroma.

The relations of the prostate to its sheath and to the base of the bladder have an important practical bearing on the surgery of the prostate.

The operation of perineal prostatectomy consists essentially in the exposure of the posterior surface of the prostatic sheath from the peri- 
neum, in the incision of this fascia and stripping of it from off the prostate, and in the hemisection of the prostate and dissection of each half from the urethra and from the bladder base. It will be recognised, therefore, that the ready separation of the prostate on its posterior and lateral surfaces from its surrounding sheath of fascia is a point of special importance in this operation.

When the prostate is approached by the suprapubic route, the bladder base intervenes between the finger of the operator and the base of the prostate. Certain pathological changes take place, however, during the enlargement of the gland which overcome this difficulty. These changes I have fully discussed elsewhere, and they need not detain us here. I shall ask you to accept the statement that the enlarged prostate has pushed some part of its bulk through the lumen of the sphincter and dilated it so that only the mucous membrane of the bladder covers the intruding mass. By stripping off the mucous membrane the finger may be insinuated alongside or behind this mass through the lumen of the sphincter. The rest of the operation now consists in shelling the prostate out of its sheath. In doing so the upper end of the prostatic urethra, together with the remains of the longitudinal layer of trigone muscle, are torn through, the prostate is separated from the under surface of the bladder base, the ejaculatory ducts torn across, the adhesion along the anterior surface separated, and finally, the prostatic urethra severed about its junction with the membranous portion. The points of difficulty are just those that would be anticipated by a study of the connections of the normal gland.

\section{The Striped Muscle of the Prostate.}

I have already referred to the non-striped sphincter of the urethra, the sphincter vesicæ, and it is necessary to consider briefly the striped muscle which is related to the prostate.

If the prostate be removed from the body, a ring of striped muscle will be found surrounding the urethra at its apex (fig. 1, H). This is a part of the compressor urethræ muscle. When traced upwards, it is found to cover the front of the apex of the prostate for a short distance, and here it is attached to the fascia on either side. Viewed from the surface of the sheath, the striped muscle appears to end here. Further dissection and microscopical sections show, however, that it dips in beneath the sheath at this point. I have already noted that, in stripping the sheath towards the apex, coarse muscular fibres were found between the prostate and the sheath. These fibres belong to the continuation of this muscle.

If horizontal sections of the prostate be made at right angles to the 
urethra, what appears to be the apex of the organ consists of circular muscular tibres surrounding the urethra, and is therefore the upper portion of the membranous urethra. As the sections pass upward, the striped muscle is found to cover only the front of the urethra. At a slightly higher level the gland tissue begins to appear, and a wedge of non-striped muscle, the anterior commissure of the prostate, separates the striped muscle from the urethra. The striped muscle here lies between the anterior commissure and the anterior layer of the sheath. In this situation the layer of striped muscle passes upwards on the front of the prostate as far as the base of the gland.

A section of the prostate at the level of the verumontanum (fig. 2) shows a thin but definite layer of striped muscle lying on the front of the organ between it and the anterior layer of the sheath. Traced laterally, a few of these fibres stray among the non-striped fibres of the prostatic stroma, but the layer may be traced on each side on the surface of the capsule as far back as the level of the urethra. Here the fibres gradually diminish and disappear.

In a vertical sagittal section of the prostate this striped muscle may be traced upwards to the point where the circular bladder muscle joins the sphincter vesicæ in front of the base of the prostate (figs. 5, 6).

Henle described this muscle under the name "sphincter vesicæ externus." His description is not very full, but the sections of the prostate which he draws illustrate the layer. I have not observed, in my sections, the striped muscle fibres which this author traced along the posterior surface of the urethra as far as the verumontanum, and in my sections the layer passes higher on the anterior surface than Henle's drawings would indicate. This author did not of course discuss its relation to capsule and sheath.

The functional importance of this striped muscle as a sphincter of the urethra is difficult to estimate.

It appeared to me to be significant that in a specimen that I recently described, ${ }^{1}$ where the walls of the "prostatic cavity" were examined two years after the operation of prostatectomy, the amount of these striped muscle fibres in the sheath seemed much in excess of what I had observed in the normal gland.

Of the surgical importance of the striped muscle surrounding the urethra at the apex of the gland I have no doubt. I do not intend to enter into the much discussed question as to whether the true sphincter of the bladder is the non-striped muscle at the internal meatus, or the striped muscle surrounding the urethra lower down, but I may state Brit. Med. Jour., Oct. 7, i905. 
my opinion that after the operation of suprapubic prostatectomy, the striped muscle performs a very inportant part in retaining the urine. In some of the patients on whom I had performed prostatectomy, I passed the fine catheter of a Guyon's syringe into the cavity left by removal of the prostate. As soon as the bulbous end of the catheter passed the constrictor urethræ into the "prostatic cavity," the urine began to drip away. This would show that after suprapubic prostatectomy the striped sphincter takes on, at least, the major part of the retentive function. ${ }^{1}$

In my opinion this is a weighty argument against the perineal drainage of the cavity after suprapubic prostatectomy, as has been suggested; and further, this explains a fact, which I think is undoubted, that the control of the urine after prostatectomy is more often imperfect after the perineal operation than.after the suprapubic.

\section{The Prostatic Plexus.}

The relation of the plexus of veins to the prostate is a subject of vital surgical interest.

The dorsal vein of the penis passes backwards under the pubic arch to disappear in the tissues covering the front of the prostate, and its further course is best studied by removing the pelvic organs from the body. It is then found that this vein has passed on singly or divided in two, and the openings of these channels are found in the front of the prostate a little way above the apex of the organ, just below the line along which the visceral layer of pelvic fascia meets that organ. On slitting up the veins a number of channels are found lying on the front of the prostate These pass upwards towards the base of the organ, communicating with each other by lateral branches.

Arrived at the base, a number of smaller venous channels pass outwards on each side around the junction of the bladder and prostate, and thus form a figure resembling somewhat the letter $\mathrm{Y}$, the vertical stem of which lies upon the anterior surface of the prostate, while the arms of the Y embrace the junction of bladder and prostate on each side (figs. 7, 8). Thence they

1 This was not, however, invariably the case, for the "prostatic cavity" in some of these cases was empty when the bladder was full, and, moreover, no urine was left behind in this cavity immediately after the bladder had been voluntarily emptied. One may conclude that in these cases the bladder sphineter had regained its function, and also that there was sufficient contractile power in the wall of the prostatic carity to empty it completely of urine. The latter function may perhaps be referred to the striped muscle fibres which I have described in the wall of the cavity. 
pass upwards and outwards to join the internal iliac veins. The vertical stem of the $\mathrm{Y}$ represents the prostatic plexus, while the arms are the main channels of the vesico-prostatic plexuses. Dissection of the veins of the prostatic plexus is a matter of some difficulty, for they are firmly embedded in the tissue forming the anterior layer of the prostatic sheath.

The number and arrangement of these veins varied a good deal in the specimens I dissected. Three or four large intercommunicating channels were a common occurrence. At the base a transverse communication was usually observed.

The lateral extent of the sinuses seldom passed much beyond the

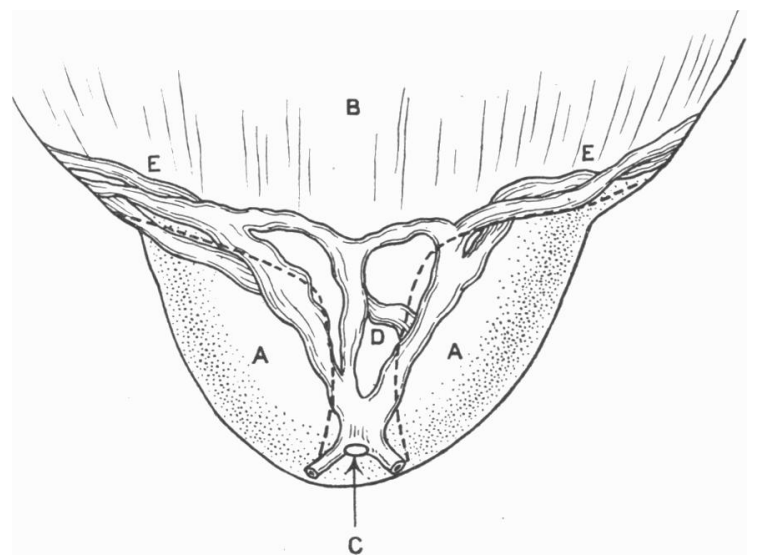

Fis. 7.-Prostatic plexus of veins.

\footnotetext{
A, Anterior surface of prostate. B, Bladder. C, 'Termination of dorsal vein of
penis. D, Prostatic plexus. E, E, Vesico-prostatic plexuses. The dotted line shows line of attachnent of fascia.
}

vertical line of reflexion of the sheath on the front of the prostate. The veins were therefore, for the most part, embedded in the thick compact anterior layer of the sheath, and the lateral layers of the sheath might be reflected from off the prostate without damaging any vein of considerable size, while the posterior layer of the sheath was quite free from veins of any importance. At the apex of the prostate a large vein passed outwards and backwards on each side.

On making horizontal sections through the prostate, these veins were seen to be embedded among the tissues forming the anterior layer of the sheath, and between this part of the sheath and the stroma of the prostate was the thin layer of striped muscle which has already claimed attention.

The arms of the $\mathrm{Y}$ forming the vesico-prostatic plexuses consisted of many veins of much smaller calibre than those of the ascending stem. 
These might be seen without dissection lying upon the surface of the bladder, just above the attachment of the rectovesical fascia, and receiving the veins from the wall of the bladder. Larger veins were placed more deeply in the angle between the prostate and the bladder, and these appeared to be the direct continuation of the sinuses of the prostatic plexus. Veins passed upwards into those from the lobes of the prostate, but the greater number of these prostatic veins appeared to pass out to join the plexus at the point of junction of the posterior and lateral surfaces and the

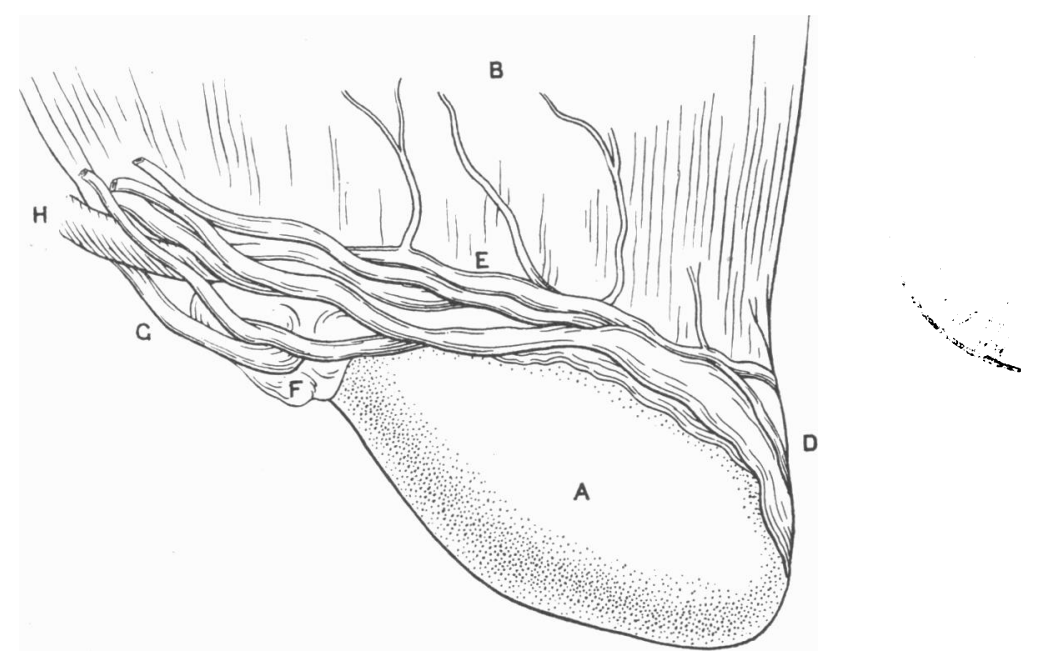

FIr. 8. - Prostatic plexus of veins, side view.

A, Right lobe of prostate. B, Bladder. D, Prostatic plexus on anterior surface of prostate. E, Vesico-prostatic plexus. F, End of right seminal vesicle. $G$, Vas deferens. H, Right ureter.

base. Towards the posterior part of the prostate these plexuses came into relation with the end of the seminal vesicles, the vasa deferentia, and the lower ends of the ureters, and received veins surrounding these structures (fig. 8).

Some variations were found in different subjects. Sometimes the vertical stem of the $\mathrm{Y}$ was short, and the arms began to.. spread outwards before reaching the base of the prostate. The veins were thus spread out over a greater surface of the front of the prostate. The prostate varies a good deal in size within normal limits, and it is in the longer prostates that the arrangement described is best seen. In small, short, poorly developed glands the vertical portion of the plexus is much shortened.

It will be seen, therefore, that the prostatic plexus comes into relation 
with the prostate only along the anterior surface of that organ, while the vesico-prostatic plexus lies above the level of the prostate. Further, the prostatic plexus is embedded between the fibres of the thick anterior layer of the sheath, and does not lie between the sheath and the capsule. This view of the prostatic plexus differs very materially from the commonly accepted descriptions. I had already made my dissections and notes upon these veins when Dr Proust of Paris drew my attention to his thesis of 1900 , in which he had pointed out that the veins lay between the layers of the sheath and not between the sheath and capsule. ${ }^{1}$

The surgical importance of these observations is obvious. In perineal prostatectomy the posterior surface of the prostatic sheath is exposed and incised, and on this aspect no veins of any importance are encountered.

In suprapubic prostatectomy the danger of hæmorrhage from the prostatic plexus was, until a comparatively recent date, held to be imminent. It was said, and, according to the usually accepted description of the course and position of the prostatic plexus, with some logic, that if the entire prostate were removed, the prostatic veins lying between the capsule and the sheath must be torn through and lead to fatal hæmorrhage. When it is realised that these venous channels lie between the layers of the sheath on the front of the prostate, and do not course between the capsule and the sheath, and further, that at the side of the organ they are high up out of danger, the feasibility of such a complete operation becomes evident.

\section{The Prostatic Urethra.}

I shall only touch upon one point in regard to the prostatic urethra, for I have already discussed the non-striped and striped muscle sphincters which relate to this part of the canal.

Examination of sagittal and horizontal sections through the prostate has given me the impression that this part of the urethra is by no means the straight vertical tube it is commonly considered. A section in the long axis of the tube shows that the first part of the tube, from the bladder opening to the verumontanum, is straight and vertical. At the verumontanum, however, the urethra begins to curve forwards, and the remaining part of its course is as much forwards as downwards.

I have had no opportunity of examining frozen sections, so that some fallacy may underlie this observation, but the curve forwards of the lower part of the prostatic urethra was so constant in different subjects, that the description is probably reliable. Horizontal sections of the prostate show

1 This author quotes, in his work on prostatectomy, published in 1904, a description of the course of these veins by Ziegler, which is somewhat similar to that I. have given. 
that at the entrance of the bladder the urethra lies upon the same plane as the anterior borders of the lateral lobes. From this level to the verumontanum it gradually sinks backwards in relation to the glandular tissue, so that at the latter level it is midway between the anterior and the posterior surfaces of the organ. From this point it passes more and more towards the front of the organ as the gland tubules disappear.

Let me say one word in regard to the clinical anatomy of the prostatic urethra. I have previously shown ${ }^{1}$ that in the majority of cases of suprapubic prostatectomy the prostatic urethra is removed, with the exception of a small strip which represents the posterior wall of the canal from the membranous urethra up to the verumontanum, and this is left adherent to the sheath.

I have examined many specimens since I made the statement, and I am convinced that this is a rule from which there are but few exceptions.

The accepted theory of the act of micturition is that a few drops of urine are forced into the sensitive prostatic urethra from the distended bladder, and that from this mucous membrane the whole reflex of micturition is initiated.

If the prostatic urethra is removed, whence comes the sensation which initiates the reflex?

I have questioned patients after the operation as to their sensations, and they invariably state that the desire to micturate differs in no way from that which they experienced before the urethra was mutilated.

Is it possible that the sensation originates in the strip of mucous membrane that is left behind? I hardly think that this is likely, for in some cases this part of the urethral wall is removed also, and the patients suffer from no disability in regard to micturition. I think it is probable that we shall have to rearrange our ideas in regard to the reflex act of micturition if these observations are correct.

\section{The Arrangement of the Gland Tissue.}

The gland tubules lie embedded in a densely woven stroma of nonstriped muscle. There is no very distinct circular arrangement of the fibres of the stroma around the individual tubules. At the surface of the organ there is an area of stroma where no gland tubules can be seen (fig. 2). This area varies in breadth; in some parts the tubules approach nearly to the surface, in others they lie well back so as to leave a broad rim unoccupied. The fibres at this part are more circular in their arrangement than they are

1 Medico-Chirurgical Transactions, London, 1904; Archives of the Middlesex Hospital, vol. iv., 1905 ; British Medical Journal, July 9, 1904.

VOL. XL. (THIRD SER. VOL. I.) -APR. 1906. 
elsewhere in the organ. This rim of stroma is the true capsule of the prostate. It cannot be dissected away without injury to the prostatic tubules, for it is a part of the stroma and intimately connected with the intertubular stroma. I have not observed the bands of tissue which are said to pass inwards from the capsule towards the urethra. The tubules are merely set in a meshwork of stroma, and are much less regular in their arrangement than one would expect from some descriptions.

The distribution of gland tissue varies at different levels. A section at the apex of the organ shows the urethra surrounded by striped muscle. At a slightly higher level the gland tissue begins to appear, and is found in small amount on each side of the urethra, while a few tubules may be found behind that tube. Still higher up the lateral masses of gland tissue increase in dimensions, and here a thin band of gland tissue unites the lateral lobes behind the urethra.

At the level of the verumontanum the gland is in the form of two masses which lie on either side of the urethra, and a broad tract of gland tissue unites these behind the canal (fig. 2). Here the ejaculatory ducts and sinus pocularis begin to pass backwards and indent the uniting band of gland tissue. Horizontal sections above this level show the ejaculatory ducts and a surrounding sheath of non-striped muscle passing backwards, and another band of gland tissue appears between them and the urethra, and this increases so that at the upper limit of the prostate the gland tissue is in the form of a horse-shoe formed by the lateral lobes on either side, and this posterior band connecting them behind the urethra.

The wedge of gland tissue which lies between the receding ejaculatory ducts and the urethra, and forms the connecting link between the upper extremities of the lateral lobes, corresponds to the median lobe of Sir Everard Home. There was no separation of this portion into a special lobe in my specimens.

In front of the urethra, along the whole length of the prostate, is a vertical wedge of non-striped muscle tissue. This anterior commissure separates the two lateral lobes. It was present in all the specimens I examined, although it varied a good deal in breadth, and in one subject the lateral lobes approached each other so closely in front of the urethra that the commissure was scarcely demonstrable at the level of the verumontallum.

In most specimens a few small gland tubules were embedded in the anterior commissure, but it was difficult to judge whether these opened upon the anterior wall of the urethra or were merely prolongations of tubules from the lateral lobes. 


\section{The Seminal Vesicles.}

I shall close with a brief reference to the position and relations of the seminal vesicles. I confess that on commencing clinical work I was firmly imbued with the idea that the seminal vesicles passed upwards and outwards along the posterior wall of the bladder, diverging slightly in their course, and that only a small part of these organs was palpable by the finger in the rectum, the remaining half or more being out of reach. This impression was gained from my anatomical reading, and I was therefore surprised to find that the diseased seminal vesicle was well within the reach of my finger to the whole of its extent. 'This led me to examine these organs when I was dissecting the prostate, and I found that my clinical observations had not led me astray. In my dissections the seminal vesicles lay along the upper border of the prostate and passed out in a transverse direction on each side for a variable distance beyond the lobes of that organ (fig. 9). The outer end of the vesicles turned slightly upwards as they passed round the sides of the bladder. Above each vesicle was the corresponding vas deferens, the ampulla of which rested on the border and upper surface of the vesicle. Only at the outer end of the seminal vesicle did the duct curve upwards to cross the lower end of the ureter. The ureters disappeared beneath the vas deferens and the outer end of the seminal vesicle, but could sometimes be dissected just as they entered the bladder wall on the inner side of the vasa deferentia.

The vesicles and vasa were invariably bound down to the bladder wall by a firm and well-defined layer of fascia which, when dissected, passed down to be attached along the margin of the base of the prostate.

The relation of the peritoneum to these organs will be seen by referring to the accompanying drawing. The peritoneum of the rectovesical pouch descends so as to cover the vasa deferentia, and about one-half of the breadth of the vesicle. The lateral extent of this pouch gives a peritoneal covering to about one-half of the length of the vesicle on each side.

The clinical importance of this is obvious, for it is realised that the seminal vesicle is well within the reach of a finger in the rectum.

I do not doubt that this relation of the vesicles is familiar to many or all of you, but it has not yet found its way into anatomical text-books, and I take this opportunity of drawing your attention to it.

The relation of the vesicles to the bladder base is of considerable importance to the surgeon, and especially where the cystoscope is used.

I have mapped out on the base of the bladder the outlines of the underlying prostate and seminal vesicles. You will see that the vesicles underlie 
the posterior part of the trigone, and extend beyond it posteriorly and laterally.

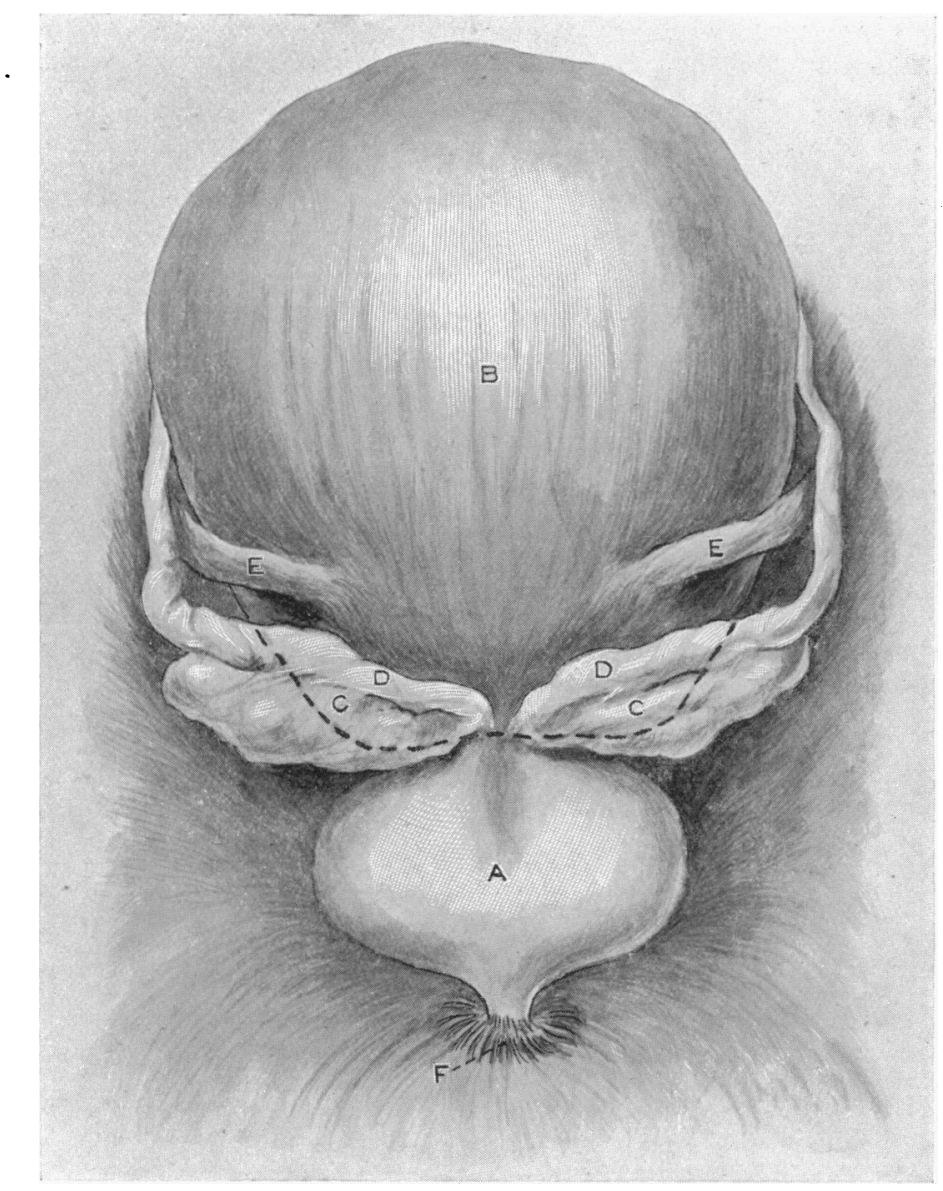

F1G. 9.-Dissection of posterior surface of bladder and prostate, showing structures in relation to the anterior wall of the rectum. $\frac{5}{8}$.

A, Prostate. B, Bladder. C, Seminal vesicles. D, Ampulla of vas deferens. E, Ureter. $\mathrm{F}$, Constrictor urethral surrounding membranous urethra. The dotted line shows relation of the peritoneal pouch of Douglas to these structures.

(The drawing shows the ureters too high up. The upper border of the prostate is horizontal and not rounded off as here depicted.)

The outline, more accurately stated, commences at the centre of the trigone half an inch behind the internal meatus and passes outwards, sweeping round the opening of the ureter about a quarter or half an inch 
from the opening, and then passing inwards behind the inter-ureteral bar of Mercier to the middle line, where it dips down as far as the posterior margin of that bar. If a similar line be drawn on the other side, the vesicles will be mapped out. From tip to tip the vesicles measured about two inches across (one- and fifteen-sixteenths) in this specimen. From the internal meatus to each tip one and a half inches.

These numbers are merely tentative, they require to be corroborated by a series of observations before being taken as the average measurements.

You will realise how difficult is the accurate palpation of the trigone of the bladder by the finger in the rectum when the prostate underlies the anterior half and the seminal vesicles the posterior half.

I must tender my grateful thanks to Dr R. A. Young of the Middlesex Hospital, and to Mr J. R. Lunn of the Marylebone Intirmary, for supplying me with material for dissection; and also to $\mathrm{Mr} \mathrm{A}$. G. R. Foulerton for facilities for carrying out the work in the clinical laboratories of the Middlesex Hospital. I would further express my thanks to Mr G. L. Cheatle, in whose laboratory were cut some of the sections from which fig. 6 was constructed. 